\title{
Estimation of the efficiency of Japanese hospitals using a dynamic and network data envelopment analysis model
}

\author{
Hiroyuki Kawaguchi • Kaoru Tone • Miki Tsutsui
}

Received: 17 November 2012 / Accepted: 15 July 2013 / Published online: 13 August 2013

(C) The Author(s) 2013. This article is published with open access at Springerlink.com

\begin{abstract}
The purpose of this study was to perform an interim evaluation of the policy effect of the current reform of Japan's municipal hospitals. We focused on efficiency improvements both within hospitals and within two separate internal hospital organizations. Hospitals have two heterogeneous internal organizations: the medical examination division and administration division. The administration division carries out business management and the medicalexamination division provides medical care services. We employed a dynamic-network data envelopment analysis model (DN model) to perform the evaluation. The model makes it possible to simultaneously estimate both the efficiencies of separate organizations and the dynamic changes of the efficiencies. This study is the first empirical application of the DN model in the healthcare field. Results showed that the average overall efficiency obtained with the DN model was 0.854 for 2007 . The dynamic change in efficiency scores from 2007 to 2009 was slightly lower. The average efficiency score was 0.862 for 2007 and 0.860 for 2009. The average estimated efficiency of the administration division decreased from 0.867 for 2007 to 0.8508 for 2009 . In contrast, the average efficiency of the medical-examination division increased from 0.858 for 2007 to 0.870 for 2009 . We were unable to find any significant improvement in efficiency despite the reform policy. Thus, there are no positive
\end{abstract}

H. Kawaguchi $(\bowtie)$

Economics Faculty, Seijo University, 6-1-20 Seijo, Setagaya-ku,

Tokyo 157-8511, Japan

e-mail: kawaguchi@seijo.ac.jp

K. Tone

National Graduate Institute for Policy Studies, Tokyo, Japan

M. Tsutsui

Central Research Institute of Electric Power Industry, Tokyo, Japan policy effects despite the increased financial support from the central government.

Keywords Dynamic and network data envelopment analysis model $\cdot$ Municipal hospital $\cdot$ Efficiency $\cdot$ Production function

MSC code 90B10 network models · Deterministic $\cdot 90 \mathrm{~B} 30$ production models $\cdot 91 \mathrm{~B} 82$ statistical methods $\cdot$ Economic indices and measures

\section{Introduction}

Japanese municipal hospitals have experienced financial crises throughout the last few decades. In 2007, the Japanese government established a set of guidelines for municipal governments for reform and facilitated a restructure of hospital operations. There are 9,000 hospitals in Japan, half of which are owned by private not-for-profit organizations, and the remainder is run by public organizations. One thousand public hospitals are owned and operated by municipal governments, most of which have been losing money for some time. As Japanese local governments have huge cumulative deficits, it is important that municipal hospitals have sound financial foundations.

The master plan for the reform of Japan's municipal hospitals includes five steps from fiscal year 2007 to fiscal year 2014 as described below. First, the central government designed guidelines regarding proposed reforms and a timeframe for those reforms in 2007. The government ordered the reform of all municipals hospitals according to the guidelines. Therefore, all reforms were to start in fiscal year 2007.

Second, the central government ordered individual municipal hospitals to formulate a reform plan, including performance indicators for the evaluation of the reform within 
fiscal year 2008. The contents of the reform plan had some range of autonomy and municipal hospitals could freely select countermeasures.

Third, municipal hospitals are required to annually report the results of the reform plan to central government. The first report was submitted in fiscal year 2009 (being the first evaluation of the reform).

Fourth, municipal hospitals were required to submit intermediate reports on the results of efficiency promotion from fiscal year 2007 to fiscal year 2010 at the end of fiscal year 2011.

Fifth, municipal hospitals are required to submit a final report on the results of the individual reform plan at the end of fiscal year 2014. The fiscal year 2014 is the deadline for the reform. If the reform has not been effective, then central government will request that the municipal hospital shut down or sell the operation of the hospital.

As explained above, the guidelines of the reform mainly target hospital administration because the main objective is to reduce deficit and to reduce the amount of subsidies received from local government. The central government is more interested in the financial situation of the hospital than the quality of medical services.

The guidelines illustrate several countermeasures for the reform of municipal hospitals. Such countermeasures can be grouped into four categories. The first is the introduction of private business management systems. For example, the guidelines recommend outsourcing to private companies and the adoption of a "Private Finance Initiative". The second category is the restructuring and consolidation of the hospital organization. For example, the guidelines recommend the merging of several hospitals and the conversion of hospitals into long-term care facilities. The third category refers to a reduction in hospitals' operating costs. For example, the guidelines propose a revision of wage systems and reductions in the purchase prices of medical materials. The fourth category is an increase in revenue. For example, the guidelines recommend increasing occupancy rates and unit values per inpatient (nearly equal to "unit revenue per inpatient per day").

Municipal hospitals can choose the countermeasures from the examples in the guidelines and can include their own reform countermeasures. Individual reform plans propose the recruitment of highly skilled professionals, further education for healthcare professionals and a revision of the range of medical services. Thus, each hospital formulates its own reform plan and then self evaluates the results.

Harris [1] pointed out that a hospital can be considered as two separate firms. There are two heterogeneous internal organizations: a medical-examination division and an administration division. The administration division carries out business management activities to contain medical expenses within medical revenue. The medical-examination division provides various medical care services directly. These two organizations can be described as internal mutual exchange services. The administration division provides medical beds to the medical-examination division, and the medical-examination division repays the revenue through the use of medical beds for inpatient services.

Japanese hospitals have acute beds and long-term care beds in various ratios. The larger hospitals tend to concentrate on acute care services. In addition, physicians and surgeons are hired and paid by hospitals as in the case of National Health Service hospitals in the United Kingdom. These physicians provide services not only to inpatients but also to outpatients at the same hospitals.

For local residents, many of the problems with municipal hospitals arise through the curtailment of certain medical services. Thus, such residents are no longer able to receive specialized care at those hospitals. The chief medical officer in charge of the medical-examination division is typically the target of criticism from the stakeholders of the hospital. The administration division tends to operate from behind closed doors and avoids blame for any failures. However, previous research has not compared efficiency improvements between the two divisions.

The purpose of this study is to evaluate policy effects of the reform for municipal hospitals in Japan. We estimated efficiency scores from 2007 to 2009 not only for the hospital as a whole but also for two divisions. In addition, we consider further policy implications to address the financial problems of Japanese municipal hospitals.

The structure of this paper is as follows. The background and purpose of our study has been discussed in this first section. The methods and data analyses are discussed in the second section. The results of the analyses are presented in the third section. After the estimation of efficiency, we report the efficiency scores. The last section includes a discussion of the results and future challenges.

\section{Method and data}

\subsection{Dynamic-network data envelopment analysis (DEA)}

\subsubsection{Concept of dynamic-network DEA}

DEA is a nonparametric method used in operations research to evaluate the efficiency performance of decision-making units (DMUs). The traditional DEA model is often considered a "black-box" model (BB model), because it does not take account of the internal structure of DMUs. DEA is a popular method with which to estimate the efficiency of hospitals [2]. Several previous studies have evaluated the efficiency of Japanese hospitals using the method [3-6]. These studies used cross-sectional data from Japanese public 
hospitals and adopted largely traditional DEA approaches. Average efficiency scores ranged from 0.8869 to 0.9456 in terms of revenue efficiency [3, 4]; for technical efficiency, they ranged from 0.8585 to $0.90008[5,6]$.

As an extension of the above BB model, the "network DEA model" accounts for divisional efficiencies as well as overall efficiency in a unified framework. Through the network DEA model, we can observe not only efficiency of DMUs but also divisional efficiencies as its components. Network DEA models were first introduced by Färe and Grosskopf [7-9]. Their models have been extended by several authors. The network DEA model proposed by Lewis and Sexton [10] presents a multi-stage structure as an extension of the two-stage DEA model proposed in Sexton and Lewis [11]. That study solves the DEA model for each node independently. Prieto and Zofio [12] applied a network efficiency analysis within an input-output model as initiated by Koopmans [13]. Löthgren and Tambour [14] applied a network DEA model to a sample of Swedish pharmacies with organizational objectives that necessitated the monitoring of efficiency, productivity and customer satisfaction. They compared the results of the network DEA models with those of traditional DEA models. Tone and Tsutsui [15] developed this model using a slacks-based measure called the network slacks-based measure (NSBM) approach. The NSBM is a non-radial method and is suitable for measuring efficiencies when inputs and outputs may change non-proportionally.

In contrast, the dynamic DEA model can measure the efficiency score obtained from long-term optimization using carry-over variables. The traditional DEA model only focuses on a single period, therefore, the measurement of intertemporal efficiency change has long been a subject of concern in DEA. The window analysis by Klopp [16] was the first approach to account for inter-temporal efficiency change. Based on Malmquist [17], Färe et al. [9] developed the Malmquist index in the DEA framework. The dynamic DEA model proposed by Färe and Grosskopf [8] is the first innovative scheme to formally deal with these interconnecting activities. Tone and Tsutsui [15] extended their model within the slacks-based measurement framework proposed by Tone [18] and Pastor et al. [19]. Hence, the model is non-radial and can deal with inputs/outputs individually, which enables us to obtain non-uniform input/output factor efficiencies. This is contrary to radial approaches, which assume proportional changes in inputs/outputs and provide only uniform input/output factor efficiency.

The dynamic-network DEA model (DN model) takes into account the internal heterogeneous organizations of DMUs, where divisions are mutually connected by link variables and trade internal products with each other. This DN model with can evaluate (1) the overall efficiency over the entire observed term, (2) dynamic change in the period efficiency and (3) dynamic change in the divisional efficiency. In addition, each DMU has carry-over variables that take into account a positive or negative factor in the previous period.

We employed a dynamic DEA model involving the network structure proposed by Tone and Tsutsui [20]. This model has the huge advantage of being able to evaluate the policy effect on the individual divisions of each DMU. Tone and Tsutsui [20] provides detailed information about the notation of the DN model.

\subsubsection{Formulas for efficiency in the dynamic-network DEA}

Notation of inputs, outputs, links, and carry-overs We are dealing with $n$ DMUs $(j=1, \ldots, n)$, which consist of $K$ divisions $(k=1, \ldots, K)$ over $T$ time periods $(t=1, \ldots, T)$. Let $m_{k}$ and $r_{k}$ be, respectively, the numbers of inputs and outputs to division $k$. We denote the link leading from division $k$ to division $h$ by $(k, h)_{l}$ and the set of links by $L_{k h}$. The observed data are as follows:

$x_{i j k}^{t} \in R_{+}\left(i=1, \ldots, m_{k} ; j=1, \ldots, n ; k=1, \ldots, K ; t=1, \ldots, T\right) \quad$ is the input resource $i$ to $\mathrm{DMU}_{j}$ for division $k$ in period $t$, and $y_{r j k}^{t} \in R_{+}\left(r=1, \ldots, r_{k} ; j=1, \ldots, n ; k=1, \ldots, K ; t=1, \ldots, T\right) \quad$ is the output product $r$ from $\mathrm{DMU}_{j}$, division $k$ in period $t$.

If some outputs are undesirable, we treat them as inputs to division $k$.

$$
z_{j(k h)_{l}}^{t} \in R_{+}\left(j=1, \ldots, n ; l=1, \ldots, L_{k h} ; t=1, \ldots, T\right) \text { rep- }
$$

resents the linking intermediate products of DMUj from division $k$ to division $h$ in period $t$, where $L_{k h}$ is the number of items in the links from $k$ to $h$.

$$
z_{j k_{l}}^{(t, t+1)} \in R_{+}\left(j=1, \ldots, n ; l=1, \ldots, L_{k} ; k=1, \ldots, K, t=1, \ldots, T-1\right)
$$

is the carry-over of DMUj , at division $k$ from period $t$ to period $t+1$, where $L_{k}$ is the number of items in the carry-over from division $k$.

Expression for $D M U_{o} \operatorname{DMU}_{o}(o=1, \ldots, n) \in P^{t}$ can be expressed as follows. The input and output constraints are

$$
\begin{aligned}
& \mathbf{x}_{o k}^{t}=\mathbf{X}_{k}^{t} \lambda_{k}^{t}+\mathbf{s}_{k o}^{t-} \quad(\forall k, \forall t) \\
& \mathbf{y}_{o k}^{t}=\mathbf{Y}_{k}^{t} \lambda_{k}^{t}-\mathbf{s}_{k o}^{t+} \quad(\forall k, \forall t) \\
& \mathbf{e} \lambda_{k}^{t}=1 \quad(\forall k, \forall t) \\
& \lambda_{k}^{t} \geq \mathbf{0}, \quad \mathbf{s}_{k o}^{t-} \geq \mathbf{0}, \quad \mathbf{s}_{k o}^{t+} \geq \mathbf{0}, \quad(\forall k, \forall t)
\end{aligned}
$$

where

$\mathbf{X}_{k}^{t}=\left(\mathbf{x}_{1 k}^{t}, \ldots, \mathbf{x}_{n k}^{t}\right) \in R^{m_{k} \times n}$ and $\mathbf{Y}_{k}^{t}=\left(\mathbf{y}_{1 k}^{t}, \ldots, \mathbf{y}_{n k}^{t}\right) \in R^{r_{k} \times n}$ signify the input and output matrices and $\mathbf{s}_{k o}^{t-}$ and $\mathbf{s}_{k o}^{t+}$ are, respectively, the input and output slacks.

With regard to the linking constraints, there are several options, for which we present four possible cases. There are, for example, "as input" and "as output" link value cases.

In the "as input" link value case, the linking activities are treated as an input to the succeeding division, and excesses are accounted for in the input inefficiency: 


$$
\mathbf{z}_{o(k h) i n}^{t}=\mathbf{Z}_{(k h) i n}^{t} \lambda_{k}^{t}+\mathbf{s}_{o(k h) i n}^{t} \quad\left((k h) \text { in }=1, \ldots, \text { linkin }_{k}\right)
$$

where $\mathbf{s}_{o(k h) i n}^{t} \in R^{L_{(k h) i n}}$ represents slacks and is non-negative, and linkin $_{k}$ is the number of "as input" links from division $k$.

In the "as output" link value case, the linking activities are treated as an output from the preceding division, and shortages are accounted for in the output inefficiency: $\mathbf{z}_{o(k h) o u t}^{t}=\mathbf{Z}_{(k h) o u t}^{t} \lambda_{k}^{t}-\mathbf{s}_{o(k h) o u t}^{t} \quad\left((k h) o u t=1, \ldots\right.$, linkout $\left._{k}\right)$

where $\mathbf{s}_{o(k h) o u t}^{t} \in R^{L_{(k h) o u t}}$ represents slacks and is non-negative and linkout $_{k}$ is the number of "as output" links from division $k$.

We classify carry-over activities into four categories as follows. Corresponding to each category of carry-over, we derive the following equations:

$$
\begin{aligned}
& z_{\text {oklgood }}^{(t, t+1)}=\sum_{j=1}^{n} z_{j k_{l} \text { good }}^{(t, t+1)} \lambda_{j k}^{t}-s_{\text {oklgood }}^{(t, t+1)} \quad\left(k_{l}=1, \ldots, \operatorname{ngood}_{k} ; \forall k ; \forall t\right) \\
& z_{\text {ok }{ }_{l} \text { bad }}^{(t, t+1)}=\sum_{j=1}^{n} z_{j k_{l} \text { bad }}^{(t, t+1)} \lambda_{j k}^{t}+s_{o k_{l} \text { bad }}^{(t, t+1)} \quad\left(k_{l}=1, \ldots, \text { nbad }_{k} ; \forall k ; \forall t\right) \\
& z_{o k_{l} \text { free }}^{(t, t+1)}=\sum_{j=1}^{n} z_{j k_{l} \text { free }}^{(t, t+1)} \lambda_{j k}^{t}+s_{o k_{l} \text { free }}^{(t, t+1)} \quad\left(k_{l}=1, \ldots, \text { free }_{k} ; \quad \forall k ; \quad \forall t\right) \\
& z_{o k_{l} f i x}^{(t, t+1)}=\sum_{j=1}^{n} z_{j k l f i x}^{(t, t+1)} \lambda_{j k}^{t}\left(k_{l}=1, \ldots, n f i x_{k} ; \quad \forall k ; \quad \forall t\right) \\
& s_{\text {ok } k_{l} \text { good }}^{(t, t+1)} \geq 0, \quad s_{\text {ok } k_{l} \text { bad }}^{(t, t+1)} \geq 0 \quad \text { and } \quad s_{\text {ok } k_{\text {free }}}^{(t, t+1)} \text { : free } \quad\left(\forall k_{l} ; \forall t\right)
\end{aligned}
$$

where $s_{o k_{l} \text { good }}^{(t, t+1)}, s_{o k_{l} \text { bad }}^{(t, t+1)}$ and $s_{o k_{l} \text { free }}^{(t, t+1)}$ represent slacks denoting, respectively, carry-over shortfall, carry-over excess, and carry-over deviation; and $n \operatorname{good}_{k}, n b a d_{k}$, and $n$ free $_{k}$ indicate, respectively, the number of desirable (good), undesirable (bad), and free carry-overs for each division $k$. The notation for data and variables is summarized in Table 1.

Objective function for overall efficiency, period efficiency, and divisional efficiency Overall efficiency is evaluated by

\begin{tabular}{|c|c|c|}
\hline \multicolumn{3}{|l|}{ Data } \\
\hline Input & $x_{i j k}^{t}$ & Input resource $i$ to $\mathrm{DMU} j$ for division $k$ at period $t$ \\
\hline Output & $y_{r j k}^{t}$ & Output product $r$ from $\mathrm{DMU} j$ for division $k$ at period $t$ \\
\hline Link & $z_{j(k h)_{l}}^{t}$ & Linking intermediate product of $\mathrm{DMU}_{j}$ from division $k$ to division $h$ at period $t$ \\
\hline Carry-over & $z_{j k_{l}}^{(t, t+1)}$ & Carry-over of $\mathrm{DMU}_{j}$ at division $k$ from period $t$ to period $t+1$ \\
\hline \multicolumn{3}{|l|}{ Variable } \\
\hline Input slack & $s_{i o k}^{t-}$ & Slack of input $i$ of $\mathrm{DMU}_{o}$ for division $k$ at period $t$. \\
\hline Output slack & $s_{r o k}^{t+}$ & Slack of output $r$ of $\mathrm{DMU}_{o}$ for division $k$ at period $t$. \\
\hline Link slack & $s_{o(k h)_{l} \alpha}^{t}$ & $\begin{array}{l}\text { Slack of link }(k h)_{l} \text { of } \mathrm{DMU}_{o} \text { at period } t . \\
\alpha \text { stands for free, as-input, and asoutput. }\end{array}$ \\
\hline $\begin{array}{l}\text { Carry-over } \\
\text { slack }\end{array}$ & $s_{o k_{l} \alpha}^{(t, t+1)}$ & $\begin{array}{l}\text { Slack of carry-over } k_{l} \text { from period } t \text { to period } t+1 \text {. } \\
\alpha \text { stands for free, good and bad. }\end{array}$ \\
\hline Intensity & $\lambda_{j k}^{t}$ & Intensity of $\mathrm{DMU}_{j}$ corresponding to division $k$ at period $t$ \\
\hline
\end{tabular}
the following program:

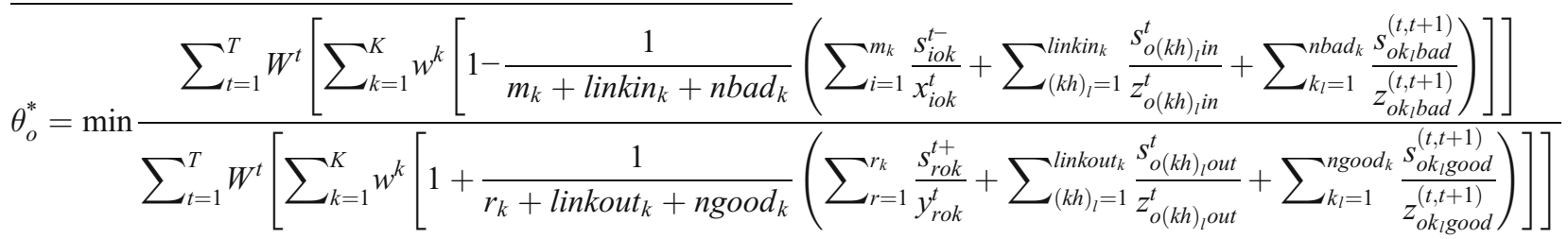

Table 1 Notation of data and variables in $\mathrm{DN}$ model 
subject to (1) to (4), where $W^{t}(\forall t)$ is the weight to period $t$ and $w^{k}(\forall k)$ is the weight to division $k$. These weights satisfy the condition $\sum_{t=1}^{T} W^{t}=1, \sum_{k=1}^{K} w^{k}=1, W^{t} \geq 0(\forall t), w^{k} \geq 0(\forall k)$. They are supplied exogenously. The numerator includes terms associated with relative slacks of inputs ("as-input" links and bad carry-overs), whereas the denominator includes relative slacks of output ("as-output" links and good carry-overs). They are weighted by the divisional weight $w_{k}$ and further by the period weight $W^{t}$, and they result in the overall efficiency $\theta_{o}{ }^{*}$. This objective function is a generalization of the slacks-based measure developed by Tone [18]. The divisional weights indicate the importance of the division, e.g., cost and manpower, whereas the period weights reflect, for example, discount rate by period. $\theta_{o}{ }^{*} \leq 1$ and $\theta_{o}{ }^{*}=1$ hold if and only if all slacks are zero. The input-/output-oriented model can be defined by dealing with the numerator/ denominator of the above objective function. Utilizing the optimal slacks obtained by solving program (5), we define the period and divisional efficiencies as follows. Period efficiency is defined by

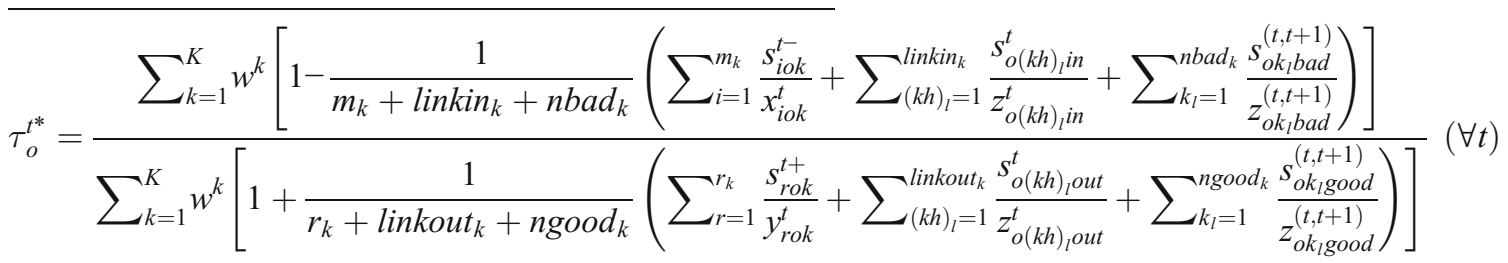

where variables on the right-hand side indicate optimal values for the overall efficiency $\theta_{o}{ }^{*}$.
Divisional efficiency is defined by

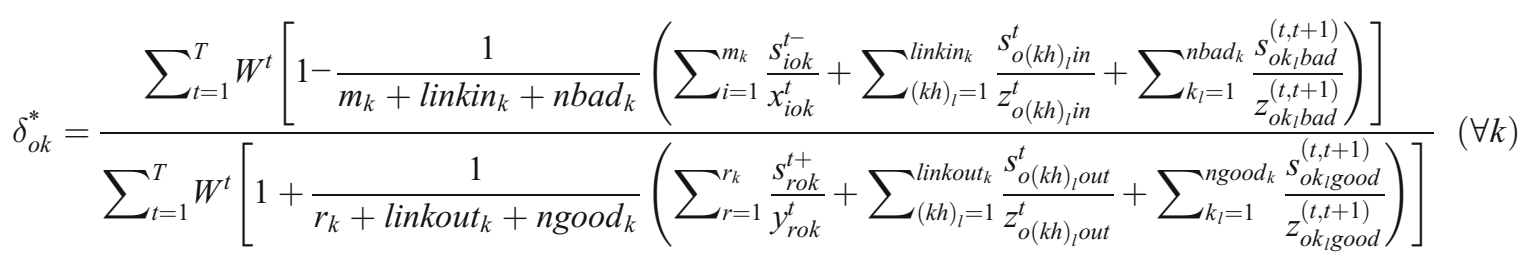

Finally, period-divisional efficiency is defined by

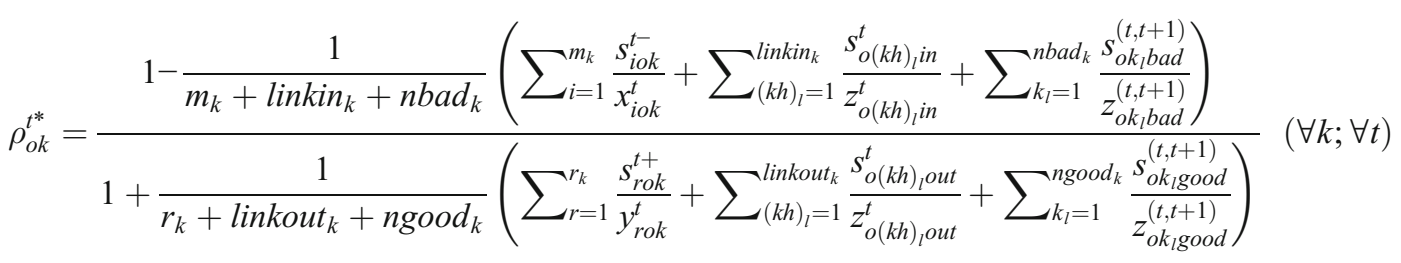

In the input-/output-oriented model, the numerator/denominator of the above formulas is applied.

\subsubsection{Adopted variables of dynamic-network DEA}

The DN model makes it possible to have a two-stage production structure in one hospital, that is, both the administration division and medical-examination division. The administration division raises funds for and maintains medical beds. The medical-examination division uses the medical beds and provides medical services. Furthermore, the medical-examination division earns medical revenue in return for medical services and the administration division collects the revenue from the medical-examination division and manages financial matters. Previous literature that adopted BB models in the study of Japanese hospitals did not consider intermediate products in a hospital. In case of the DN model, we can use link variables as intermediate products for both divisions. This benefit of the DN model (compared with the BB model) is that it makes it possible to reflect on the actual situation. We adopted two link variables in our model.

In addition, if we add variables related to the administration division in the BB model, we would suffer from inadequate correspondence between inputs and outputs. For 
example, the administration staff does not directly engage in the production of medical services. In the case of the BB model, this input may correspond with the number of inpatients as an output. However, the relationship between the administration staff and the number of inpatients would cause an undesirable bias in the efficiency estimation. Therefore, the DN model conceptually reduces bias (compared with the BB model) in the estimation of efficiency by both considering the multiple-step production structure and by excluding inadequate interactions between inputs and outputs. However, we do not consider more detailed divisions in this study. For example, we did not consider pharmaceutical or clinical laboratory divisions.

\subsection{Empirical data}

The data used in this empirical investigation concerns 112 municipal hospitals from 2007 to 2009 in a balanced panel. There are approximately 1,000 municipal hospitals in Japan and there is large heterogeneity among them. We selected municipal hospitals with more than 300 beds. Therefore, this sample may represent larger acute hospitals owned by Japanese municipals. The data were collected from the Annual Databook of Local Public Enterprise published by the Ministry of Internal Affairs and Communications. It is a legal requirement that the local chief executive of municipal governments submit audited financial statements to the ministry. Therefore, the data should be accurate. Accuracy is required for DEA because it cannot take into account measurement errors in the data. DEA also implicitly assumes the correct model specification and the correct specification of inputs, outputs and other variables.

The objective function of the administration division is to realize a sound financial situation through labor inputs and capital inputs. The objective function of the medicalexamination division is to provide a certain amount of medical services using hospital beds that are maintained by the administration division at the same hospital.

Many previous studies that have adopted BB models to examine Japanese hospitals have focused on the activities of the medical-examination division. These studies typically adopt the number of doctors and nurses as inputs and the number of inpatients and outpatients as outputs. Therefore, such studies do not contain the activities of the administration division, by way of either input variable or output variable. However, the DN model enables us to consider activities in both divisions. We can observe the activities of the administration division separately from the medical-examination division.

The inputs, outputs, links and carry-overs of the DN model are described below. For Division 1 (administration division), we adopted two labor inputs and three capital inputs. The administration division does not directly provide a medical service to patients. The division is in charge of providing medical beds to the medical-examination division and maintains a sound financial situation for the hospital. Therefore, administration staffs should manage the financial situation of the hospital. They also receive subsidies from the municipal government and manage the reimbursement of issued hospital bonds. Maintenance staffs maintain all the hospital buildings for hospital activities. As labor inputs, we used both the number of administration officers and the number of maintenance officers. All labor inputs are fulltime equivalents (FTEs). However, we did not consider staff differences in productivity and wage levels. As capital inputs, we used the interest cost for financial arrangements and municipal subsidies to cover deficits.

For the output of Division 1, we intended to adopt the "balance ratio of medical incomes to medical expenses"; the break-even point has a value of 1 and a surplus has a value exceeding 1. However, using a ratio as an input or output makes the convexity issue of DEA problematic [21]. Emrouznejad and Amin [22] recommended not using constant returns to scale when there is a ratio in the input/output variables. Therefore, we decomposed the ratio to medical income and medical expenses: the numerator was used as output for Division 1 and the denominator as input for Division 1.

For Division 2 (the medical-examination division), we adopted four labor inputs: the number of doctors, number of nurses, number of assistant nurses and number of medical technologists. All labor inputs are FTEs. For the outputs of Division 2, we adopted the number of inpatients per operation day, the number of outpatients per operation day and the number of beds in emergency units. In Japan, there is no gate-keeping system involving general practitioners. Therefore, hospitals accept a large number of outpatients to attract potential inpatients. In this study the number of beds in emergency units was used as a surrogate variable for emergency care service because we could not distinguish between emergency care patients and ordinary patients from the data source.

Previous studies regarding efficiency estimations on Japanese hospitals did not include emergency medical services. A core function of public hospitals in Japan is to ensure a quick response for emergency patients. However, some municipal hospitals have closed their emergency units to reduce costs despite the increasing need for emergency medical services. Although we consider that the evaluation of efficiency of municipal hospitals should include the number of emergency patients, we were not able to obtain numbers from the available data. Therefore, we adopted the number of emergency beds as a proxy for the number of emergency patients. This proxy variable has limitations because it did not control for the difference in severity of emergency patients, the quality of emergency medical service and the occupancy rate of the emergency beds.

The existence of a link variable is one of the key differences between the DN model and the BB model. The link variable is 
an intermediate product that acts simultaneously as an output for Division 1 and an input to Division 2. Using an intermediate product, we can evaluate multiple production steps among divisions in one DMU. Tone and Tsutsui [20] present four possible scenarios. For example, the "fixed link value case" means that the linking activities are unchanged.

We set the "number of beds" as a link variable from Division 1 to Division 2. We assumed that Division 1 is in charge of the funding and maintenance of medical beds. Division 1 supplies these beds to Division 2. Division 2 uses the medical beds and delivers medical care services to patients. We adopted a non-discretionary "fixed" link, where the linking activity remains the same. The reason for this is that it would be unusual for the medical-examination division to negotiate with the administration division to change the number of beds. The administration division also has an incentive to generate sufficient medical revenue (to offset the medical expenses) and to use all available beds.

We used "average revenue per inpatient per day" as a link variable from Division 2 to Division 1. We assumed that the average revenue is the consideration to be paid to Division 1 for the beds from Division 2. The average revenue per inpatient may represent the density of medical care services. We adopted the "as-output" link, where the linking activity is treated as an output from Division 1. The reason for this is that this matter is not negotiable between the two divisions. Division 1 should be efficient enough to provide higher density medical services under the given resource concentrations (Fig. 1).

The carry-over variable is one of the benefits of using a DN model compared with a BB model. A DMU ordinarily continues activities over several terms. Furthermore, some inter-temporal factors can affect its efficiencies. The carryover variable makes it possible to account for the effect from connecting activities between continuing terms. The carryover variable has four characteristics in Tone and Tsutsui
[20]. For example, "desirable (good) carry-over" variables are treated as outputs and a comparative shortage of carryovers is seen as inefficiency.

We set the "balance account of the public enterprise bond (hospital bond)" as an undesirable (bad) carry-over. The hospital bond was chosen as the carry-over because municipal hospitals issue these bonds to raise funds for capital investment in terms of hospital beds. The municipal hospital gradually redeems the issued bond from any revenue surplus. We adopted the "undesirable (bad)" carry-over; thus, the connecting activity from Period 1 to Period 2 is treated as an input. The reason for this is that newly built hospitals are more attractive to patients but represent a heavier fiscal burden in terms of repaying the principal. Therefore, to treat the public enterprise bond as a carry-over reflects accurately the competitive condition of the market in which patients can freely access any hospital. However, we did not consider both the average life and interest rate of the hospital bonds.

According to the first principle that a public hospital is expected to accomplish a policy goal with a minimum budget, we selected an input-oriented model. We adopted both constant returns to scale (CRS) and variable returns to scale (VRS) models in the analysis. Descriptive statistics of all variables in the analysis are provided in Table 2.

Figure 2 shows the structure of the BB model. The inputs and outputs of the BB model are exactly the same as those of the DN model. The inputs are denoted as Input 1 to Input 9. The outputs are denoted as Output 10 to Output 13 as in Table 2. The variables for links and carry-overs do not apply in the case of the BB model.

\section{Results}

The right side of Table 3 presents the key statistics of the estimated efficiency scores obtained by the DN model and

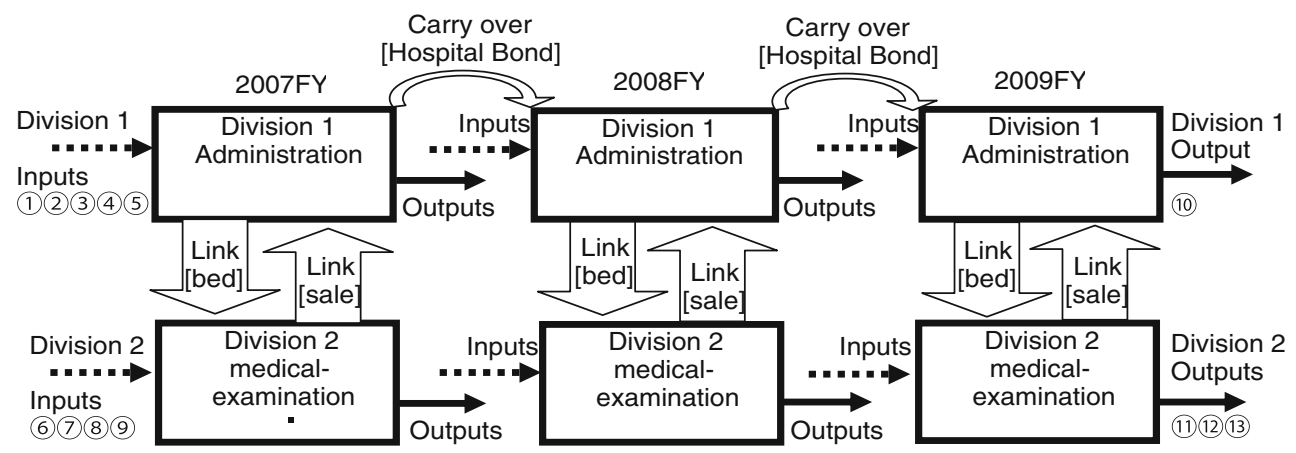

Fig. 1 Structure of the dynamic and network data envelopment analysis model. We estimated the efficiency of Japanese municipal hospitals in two parts. The first division is the administration division, which is responsible for financial management. The second division is the medical-examination division, which directly provides a medical service. There are two links between the divisions. The number of beds is a link from Division 1 to Division 2. The average revenue per inpatient per day is a link from Division 2 to Division 1. The dynamic-network data envelopment analysis model also indicates the relationship between the two divisions in terms of efficiency improvement from 1 year to the next. The carry-over variable is used to represent the inter-temporal relationship 
Table 2 Basic description of variables

\begin{tabular}{|c|c|c|c|c|c|c|c|}
\hline & & Variable names & Average & S.D. & Max & Min & Units \\
\hline \multirow[t]{6}{*}{ Division1 } & \multirow[t]{5}{*}{ Input } & (1) Number of administration officers & 29.35 & 13.14 & 89.00 & 9.00 & Person \\
\hline & & (2) Number of maintenance officers & 17.96 & 15.54 & 83.00 & 0.00 & Person \\
\hline & & (3) Interest cost per year & 510.15 & 394.23 & $1,666.92$ & 0.80 & Milion Yen \\
\hline & & (4) Subsidy from municipal & 23.68 & 17.59 & 89.70 & 2.80 & Milion Yen \\
\hline & & (5) Medical expense & 9,531 & 5,232 & 28,286 & 2,048 & Milion Yen \\
\hline & Output & (10) Medical income & 8,355 & 4,853 & 24,769 & 1,314 & Milion Yen \\
\hline \multicolumn{2}{|c|}{$\operatorname{Link}(\operatorname{Div} 1 \rightarrow \operatorname{Div} 2)$} & Number of beds & 482 & 180 & 1334 & 300 & Unite \\
\hline \multirow[t]{7}{*}{ Division2 } & \multirow[t]{4}{*}{ Input } & (6) Number of doctors & 62.17 & 35.89 & 166.00 & 6.00 & Person \\
\hline & & (7) Number of nurses & 314.41 & 152.76 & 800.00 & 79.00 & Person \\
\hline & & (8) Number of assistant nurses & 5.33 & 6.45 & 46.00 & 0.00 & Person \\
\hline & & (9) Number of medical technologist & 65.77 & 32.61 & 171.00 & 8.00 & Person \\
\hline & \multirow[t]{3}{*}{ Output } & (11) Number of inpatients per an operation day & 378.14 & 156.79 & 964.00 & 73.00 & Person \\
\hline & & (12) Number of outpatients per an operation day & 742.14 & 425.64 & 2224.00 & 19.00 & Person \\
\hline & & (13) Number of beds for emergency unites & 14.09 & 14.73 & 66.00 & 0.00 & Unite \\
\hline \multicolumn{2}{|c|}{ Link(Div2 $\rightarrow$ Div1) } & Average revenue per inpatient per day & 16,822 & 6,629 & 31,841 & 3,661 & Yen \\
\hline \multicolumn{2}{|l|}{ Carry over } & Balance account of the public enterprise bond & 752,228 & $1,109,846$ & $9,612,400$ & 0 & Thousand Yen \\
\hline
\end{tabular}

those of the BB model are shown on the left. The average efficiency score estimated by the BB model is 0.988 in 2007 and is higher than the average efficiency estimated in previous studies on Japanese municipal hospitals. We suspect that the reason for this is the higher number of variables used in the model.

On the right of Table 3, the first row shows the efficiency scores of the overall hospital organization as determined by the DN model. The second row shows the efficiency scores of the administration divisions of the sample hospitals. The third

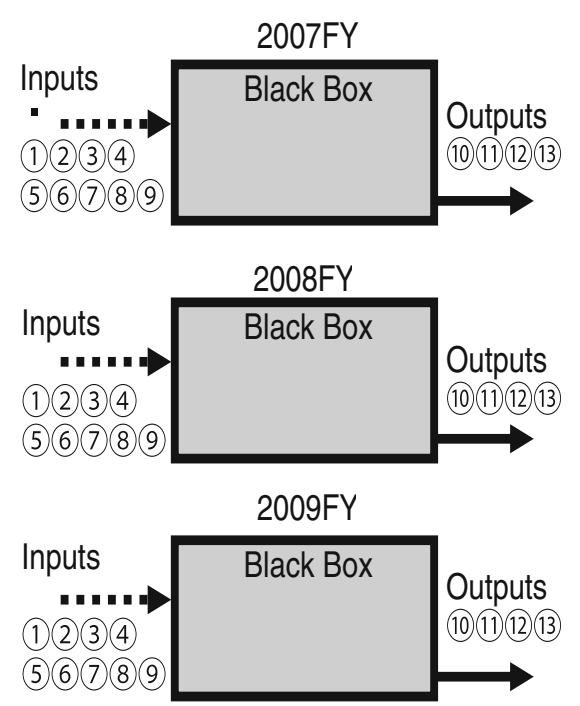

Fig. 2 Structure of the black box (BB model). The inputs and outputs of the BB model are exactly the same as those of the dynamic-network (DN model). The inputs are denoted Input (1) to Input (9). The outputs are denoted Output (10) to Output (13). The variables for links and carryover do not apply in the case of the BB model row shows the efficiency scores of the medical-examination divisions of the sample hospitals. From the results of DN model, we obtained four key findings.

First, the average overall efficiency obtained with the DN model was 0.854 (VRS model) for 2007. The average efficiency score estimated by the DN model was smaller than the average efficiency estimated in previous studies on Japanese municipal hospitals [3-6]. In the same year, the ratio of efficient DMUs was $39.0 \%$.

Second, the dynamic change in efficiency scores from 2007 to 2009 is slightly less. The average efficiency score was 0.862 for 2007 and 0.860 for 2009 (VRS model).

Third, because of the advantage of the network structure in the DN model, we can observe the efficiency change separately for different internal organizations. The average level of estimated period-divisional efficiency of the administration division decreased from 0.867 in 2007 to 0.8508 in 2009 (VRS model). In contrast, the average perioddivisional efficiency of the medical-examination division increased from 0.858 in 2007 to 0.870 in 2009 (VRS model). On average, there was no significant efficiency change in both divisions for the 3-year period.

The Pearson's product-moment correlation coefficient of period-divisional efficiency scores on 2009 between the two divisions was 0.569 (statistically significant at $p<0.01$ ). The value of the Spearman's rank-correlation coefficient was 0.597 (statistically significant at $p<0.01$ ). Thus, there was only a weak correlation between the period-divisional efficiencies in each division (Fig. 3).

In addition, we investigated individual hospitals in terms of the relationship between the dynamic changes of perioddivisional efficiencies of two divisions between 2007 and 
Table 3 Efficiency scores obtained from the DN model and BB model

\begin{tabular}{|c|c|c|c|c|c|c|c|c|c|c|}
\hline \multicolumn{5}{|c|}{ Black box DEA model } & \multicolumn{6}{|c|}{ Dynamic-network DEA model } \\
\hline Model & Year & 2007 & 2008 & 2009 & Division & Model & Year & 2007 & 2008 & 2009 \\
\hline \multirow[t]{4}{*}{ CRS-I } & Average & 0.9742 & 0.9725 & 0.9736 & Overall & CRS-I & Average & 0.7633 & 0.7714 & 0.7824 \\
\hline & $\mathrm{SD}$ & 0.0634 & 0.0610 & 0.0578 & & & SD & 0.1663 & 0.1618 & 0.1669 \\
\hline & Maximum & 1 & 1 & 1 & & & Maximum & 1 & 1 & 1 \\
\hline & Minimum & 0.6447 & 0.6807 & 0.6487 & & & Minimum & 0.3339 & 0.3175 & 0.4249 \\
\hline \multirow[t]{20}{*}{ VRS-I } & Average & 0.9876 & 0.9869 & 0.9881 & & VRS-I & Average & 0.8624 & 0.8612 & 0.8600 \\
\hline & SD & 0.0402 & 0.0361 & 0.0359 & & & SD & 0.1422 & 0.1463 & 0.1476 \\
\hline & Maximum & 1 & 1 & 1 & & & Maximum & 1 & 1 & 1 \\
\hline & Minimum & 0.7980 & 0.8140 & 0.7955 & & & Minimum & 0.4868 & 0.4879 & 0.4992 \\
\hline & & & & & Division1 (admin) & CRS-I & Average & 0.7705 & 0.7742 & 0.7810 \\
\hline & & & & & & & SD & 0.2079 & 0.2025 & 0.2088 \\
\hline & & & & & & & Maximum & 1 & 1 & 1 \\
\hline & & & & & & & Minimum & 0.2706 & 0.2268 & 0.2664 \\
\hline & & & & & & VRS-I & Average & 0.8667 & 0.8533 & 0.8508 \\
\hline & & & & & & & SD & 0.1650 & 0.1837 & 0.1813 \\
\hline & & & & & & & Maximum & 1 & 1 & 1 \\
\hline & & & & & & & Minimum & 0.3965 & 0.4061 & 0.4284 \\
\hline & & & & & Division 2 (medical) & CRS-I & Average & 0.7560 & 0.7686 & 0.7838 \\
\hline & & & & & & & SD & 0.1726 & 0.1696 & 0.1723 \\
\hline & & & & & & & Maximum & 1 & 1 & 1 \\
\hline & & & & & & & Minimum & 0.3669 & 0.4082 & 0.4122 \\
\hline & & & & & & VRS-I & Average & 0.8581 & 0.8691 & 0.8693 \\
\hline & & & & & & & SD & 0.1530 & 0.1487 & 0.1516 \\
\hline & & & & & & & Maximum & 1 & 1 & 1 \\
\hline & & & & & & & Minimum & 0.4835 & 0.5172 & 0.4795 \\
\hline
\end{tabular}

2009. We separated all sample hospitals into four areas. Area 1 is low efficiency improvement (less than or equal to 0 ) in Division 1 and high efficiency improvement (more than 0 ) in Division 2. The number of hospitals located in Area 1 was 19 (16.96\% of sample hospitals).

Area 2 is high efficiency improvement in Division 1 and high efficiency improvement in Division 2. The number of hospitals located in Area 2 was 18 (16.07\% of sample hospitals). Area 3 is low efficiency improvement in Division 1 and low efficiency improvement in Division 2. The number of hospitals located in Area 3 was 66 (58.92\% of sample hospitals). Area 4 is high efficiency improvement in Division 1 and low efficiency improvement in Division 2. The number of hospitals located in Area 4 was 9 (8.03\% of sample hospitals). These results indicated that more than half of the sample hospitals had no improvement in efficiency scores in both divisions (Fig. 4).

We also examined the difference in characteristics of the above four areas by comparing the average values of variables used to estimate the efficiency scores. We conducted Tukey's honestly significant difference test on those values.
The results showed a statistical difference only for "the number of medical technologists" between Area 3 and Area 4. Otherwise, we found no particular differences in the characteristics among the four areas (Table 4).

\section{Discussion}

There are two heterogeneous internal organizations in Japanese municipal hospitals. The first is the administration division, which is responsible for financial management. The second is the medical-examination division, which provides medical services. The purpose of this study was to separately assess the changes in the dynamic efficiency of the two internal organizations. In this study, we estimated the dynamic change of efficiency scores of Japanese municipal hospitals in terms of these two divisions (Division 1: administration division; Division 2: medical-examination division).

We employed the DN model as presented by Tone and Tsutsui [20]. Based on our results, we obtained three policy implications. First, the dynamic change in period-divisional 
Fig. 3 The scatter plot shows the estimated efficiency scores for the two divisions obtained with the dynamic and network data envelopment analysis model (DN model). The horizontal axis represents the average efficiency score of Division 1

(administration division). The vertical axis indicates the individual efficiency score of Division 2 (medical-examination division). These two efficiency scores appear to be weakly correlated

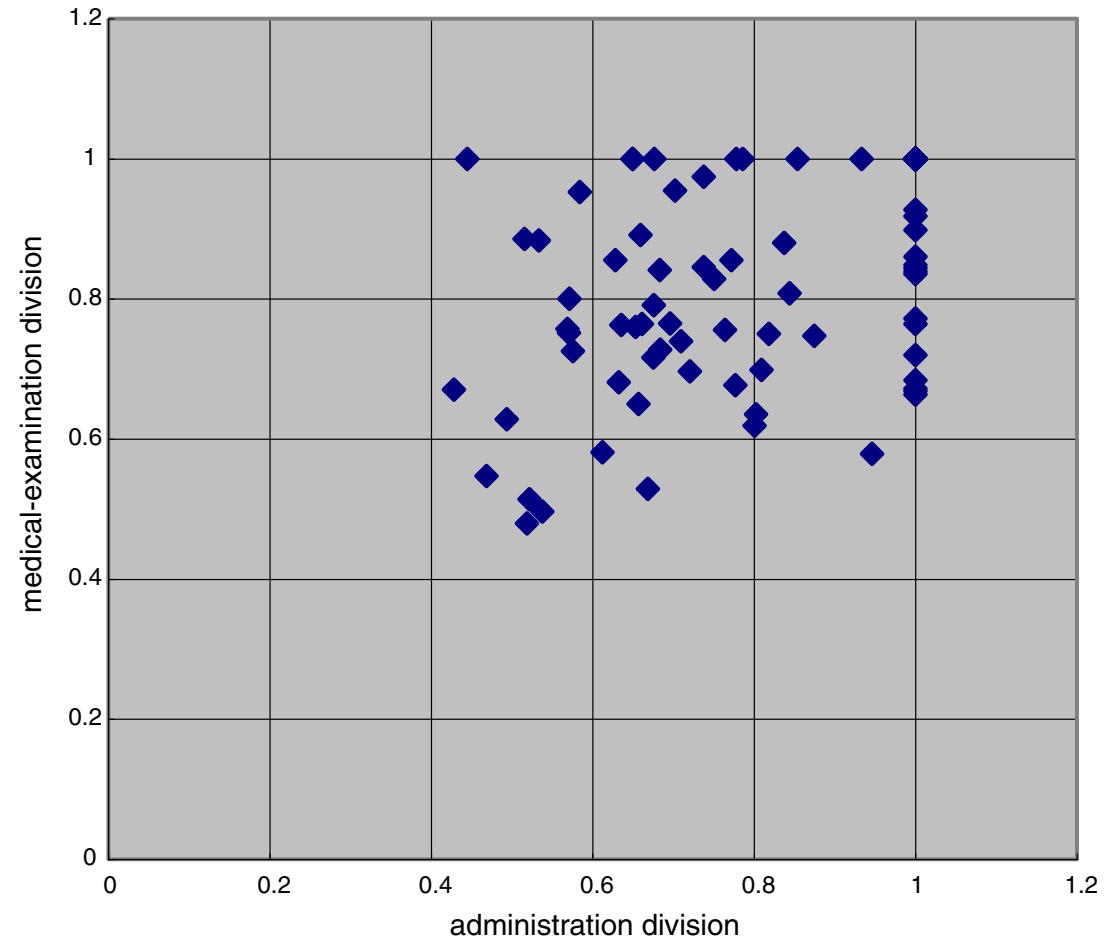

efficiency scores from 2007 to 2009 was quite small in both divisions. Therefore, on average, we could not find a positive policy effect on Japanese municipal hospitals.
Second, when we looked at individual hospitals, a DMU with an efficient medical-examination division sometimes had an inefficient administration division, and vice versa. We could
Fig. 4 The scatter plot shows the dynamic change in efficiency scores from 2007 to 2009 . The horizontal axis represents the dynamic change in the efficiency score of Division 1

(administration division). The vertical axis indicates the dynamic change of the efficiency score in Division 2 (medicalexamination division). The dynamic changes in the efficiency scores of the two divisions tend to be separated into four areas

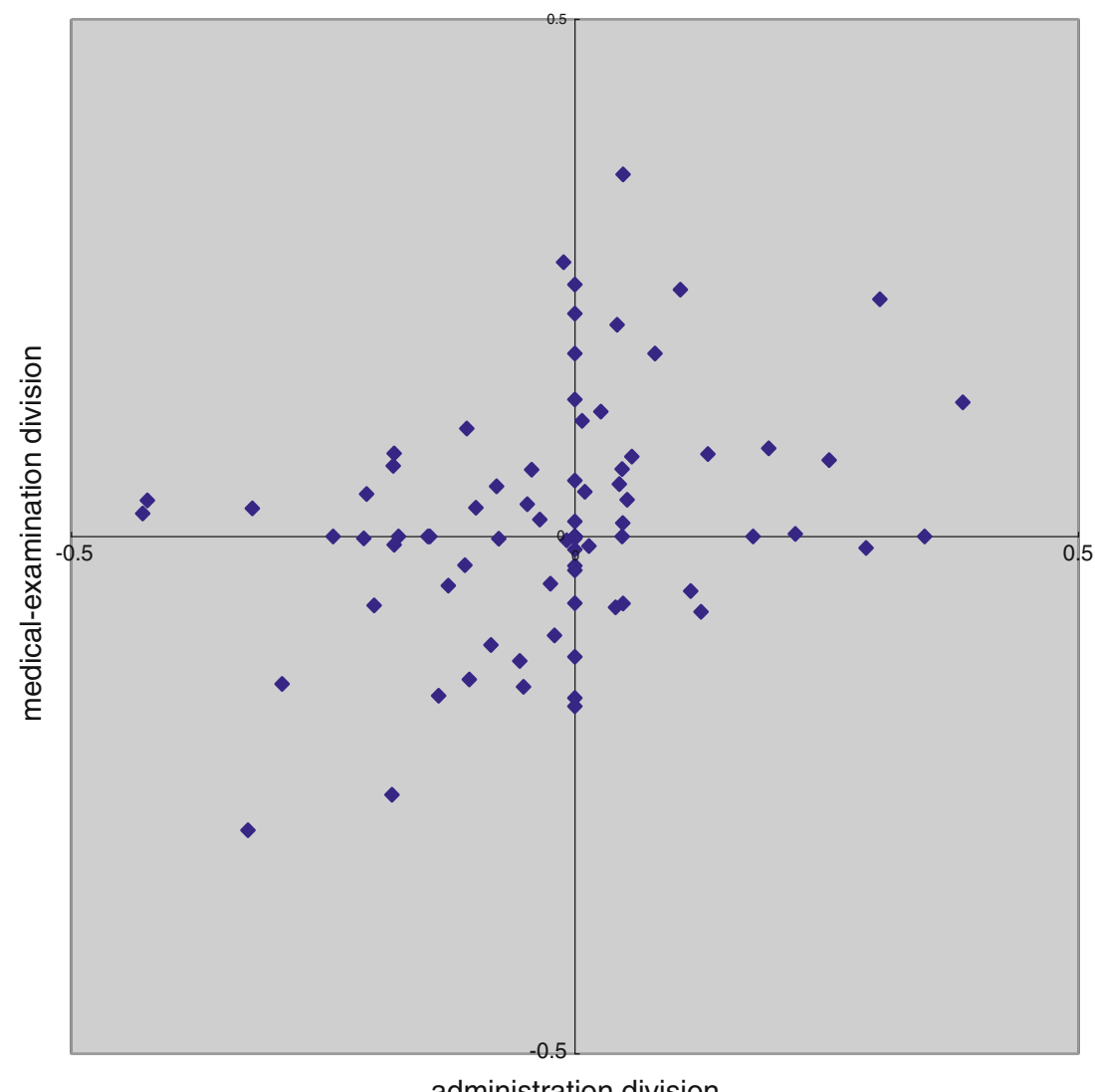


Table 4 Average values of variables in the four areas

Significance level $* p<0.05$

\begin{tabular}{lllll}
\hline & Area1 & Area2 & Area3 & Area4 \\
\hline Number of administration officers & 30.26 & 31.56 & 28.47 & 35.78 \\
Number of maintenance officers & 12.84 & 20.33 & 15.64 & 22.89 \\
Interest cost per year & 390.32 & 448.35 & 483.82 & 511.72 \\
Subsidy from municipal & 27.33 & 27.31 & 22.94 & 16.7 \\
Medical expense & $10,096,832$ & $9,304,397$ & $9,603,294$ & $12,629,624$ \\
Medical income & $8,538,576$ & $8,348,293$ & $8,655,323$ & $11,401,202$ \\
Number of beds & 474 & 439.17 & 480.09 & 559.11 \\
Number of doctors & 64.21 & 61.67 & 62.26 & 84.78 \\
Number of nurses & 313.95 & 323.33 & 311.68 & 424.56 \\
Number of assistant nurses & 2.63 & 5.28 & 4.85 & 3 \\
Number of medical technologist & 69.11 & 68.78 & $61.95 *$ & $93.78^{*}$ \\
Number of inpatients per an operation day & 346.79 & 355.5 & 371.26 & 445 \\
Number of outpatients per an operation day & 680.79 & 677.22 & 721.39 & 1015.89 \\
Number of beds for emergency unites & 9.53 & 10.5 & 15.58 & 22.67 \\
Average revenue per inpatient per day & 17,387 & 18,289 & 16,759 & 20,194 \\
Balance account of the public enterprise & 938,937 & 253,166 & 699,074 & 357,156 \\
\hline
\end{tabular}

not show strong correlation between the efficiency scores of the administration division and medical-examination division. The Pearson's product-moment correlation coefficient of the efficiency scores between the two divisions for 2009 was 0.569 (statistically significant at $p<0.01$ ). The value of the Spearman's rank-correlation coefficient was 0.597 (statistically significant at $p<0.01$ ).

Third, we also focused on the efficiency improvements of the two divisions in terms of individual hospitals. The ratio of sample hospitals where both divisions improved their efficiency score was $16.96 \%$. In contrast, the ratio of sample hospitals where both divisions maintained or had reduced efficiency scores was $58.92 \%$. The ratio of sample hospitals where the direction of change differed for the two divisions was $24.12 \%$. Among these hospitals, the hospitals' worsening efficiency scores in the administration division was twice that of hospitals' worsening efficiency score in the medicalexamination division. It would be misleading to use the change in average efficiency scores to evaluate policy effects.

From these results, we note that we did not find any significant improvement in efficiency despite the implemented policy for reform. Thus, we found that there are no positive policy effects on average despite the financial support from central government. In terms of further reform, appropriate countermeasures for different internal organizations should be implemented, taking into account the efficiency improvement to-date of each division.

The Ministry of Internal Affairs and Communication (2011) established the following two points in a sample survey of annual reports from fiscal 2009 of municipal hospitals [23]. First, almost all such hospitals did not achieve the targets that had been set for that year. Second, as an interim evaluation, the ministry concluded that reformation of municipal hospitals should be considered and effective measures implemented.

This study is the first empirical application of the DN model, and thus there are limitations that need to be addressed. For example, we were unable to use variables regarding the "quality" of medical services and the "severity" of patient condition. Therefore, we assumed that the sample hospitals would be homogeneous in terms of quality of service and severity of patient condition. We could, however, narrow the range of samples according to the number of hospital beds to ensure the homogeneity of the sample hospitals on some level. We should also examine omitted variables, e.g., the presence of large and costly medical devices such as magnetic resonance imagers. However, it is difficult to introduce criteria for determining which device should be included in the input or output of the production function. We used the number of beds in emergency units as an output and used total number of medical beds as the link variable. This double counting of medical beds could affect the results in some way.

There are other limitations regarding the control of several factors, which would influence to the estimated efficiencies. For example, the price of medical services, which is insured by public health insurance, changes every 2 years in Japan. The price increased on average by $2 \%$ in fiscal year 2008 . Many Japanese acute hospitals decided to voluntarily change their reimbursement system from "fee for service" to "per diem based on diagnosis groups". This study did not fully consider these external environmental changes in the Japanese hospital market. 
Regarding policy implications, we did not consider both the relative costs of the two divisions and the relative costs to improve efficiency in each division. For example, one division may be less efficient on average, but the other may be more costly so that a given efficiency improvement is more beneficial. When playing an active role in policy implementation, we need to consider relative costs in addition to the efficiency scores.

Future study will require a larger sample set and a more complex model.

Acknowledgments We would like to thank the attendees of the DEA Symposium 2012 for their helpful comments on our earlier study. We also appreciate the valuable comments from the reviewers. This study was supported by a Grant-in-Aid for Scientific Research (KAKENHI; grant number: 22320092).

Conflict of interest The authors declare that they have no conflict of interest in connection with this paper.

Open Access This article is distributed under the terms of the Creative Commons Attribution License which permits any use, distribution, and reproduction in any medium, provided the original author(s) and the source are credited.

\section{References}

1. Harris JE (1977) The internal organization of hospitals: some economic implications. Bell J Econ 8:467-482

2. Hollingsworth B (2008) The measurement of efficiency and productivity of health care delivery. Health Econ 17:1107-1128

3. Num S, Ishikawa K (1994) An application of DEA for labor efficiency of Japanese hospitals. Oper Res Soc Jpn 39:292-296

4. Num S, Gunji A (1994) A study on managerial efficiency in medical facilities: evaluating human resource efficiency in municipal hospitals using data envelopment analysis. J Jpn Soc Healthc Adm 131:33-39

5. Nakayama N (2003) A comparison of parametric and nonparametric distance functions: a case study of Japanese public hospitals. Iryo to Shakai 13:83-95
6. Nakayama N (2004) Technical efficiency and subsidies in Japanese public hospitals. Iryo to Shakai 14:69-79

7. Färe R, Grosskopf S (2000) Network DEA. Socio Econ Plan Sci 34:35-49

8. Färe R, Grosskopf S (1996) Intertemporal production frontiers: with dynamic DEA. Kluwer, Norwell

9. Färe R, Grosskopf S, Norris S, Zhang Z (1994) Productivity growth, technical progress, and efficiency change in industrialized countries. Am Econ Rev 84(1):66-83

10. Lewis HF, Sexton TR (2004) Network DEA: efficiency analysis of organisations with complex internal structure. Comput Oper Res $31: 1365-1410$

11. Sexton TR, Lewis HF (2003) Two-stage DEA: an application to major league baseball. J Prod Anal 19:227-249

12. Prieto AM, Zofio JL (2007) Network DEA efficiency in inputoutput models: with an application to OECD countries. Eur J Oper Res 178:292-304

13. Koopmans T (1951) An analysis of production as an efficient combination of activities. In: Koopmans $\mathrm{T}$ (ed) Activity analysis of production and allocation, Cowles Commission for Research in Economics, Monograph, vol 13. John Wiley and Sons, New York

14. Löthgren M, Tambour M (1999) Productivity and customer satisfaction in Swedish pharmacies: a DEA network model. Eur J Oper Res 115:449-458

15. Tone K, Tsutsui M (2009) Network DEA: a slacks based measurement approach. Eur J Oper Res 197:243-252

16. Klopp GA (1985) The analysis of the efficiency of production system with multiple inputs and outputs, Ph.D. dissertation. University of Illinois at Chicago, Industrial and System Engineering College

17. Malmquist S (1953) Index numbers and indifference surfaces. Trabajos de Estadistica 4(2):209-242

18. Tone K (1999) A slacks-based measure of efficiency in data envelopment analysis. Eur J Oper Res 130(3):498-509

19. Pastor JT, Ruiz JL, Sirvent I (1999) An enhanced DEA Russell graph efficiency measure. Eur J Oper Res 115(3):596-607

20. Tone K, Tsutsui M (2014) Dynamic DEA with network structure: a slacks-based measure approach. Omega 42(1):124-131

21. Hollingsworth B, Smith PC (2003) The use of ratios in data envelopment analysis. Appl Econ Lett 10:733-735

22. Emrouznejad A, Amin GR (2009) DEA models for ratio data: convexity consideration. Appl Math Model 33(1):486-498

23. Ministry of Internal Affairs and Communication (2011) Results from a survey of implementation of the reformation plans of municipal hospitals 